\title{
POSSIBILIDADES DE INSUBORDINAÇÃO CRIATIVA NO ENSINO DE ESTATÍSTICA
}

\author{
POSSIBILITIES OF CREATIVE INSUBORDINATION IN STATISTICS TEACHING
}

\author{
Leandro de Oliveira Souza \\ Universidade Federal de Uberlândia / Faculdades de Ciências Integradas do Pontal \\ (FACIP), olilean@gmail.com
}

\section{Resumo}

As ações de insubordinação criativa são atos políticos que ocorrem quando se rompe com regras preestabelecidas, visando obter progresso e mudanças na sociedade com foco na justiça social. Este texto visa relatar um projeto de pesquisa que buscou novas abordagens para ensinar Estatística, por meio de atividades de investigação, exploração, tratamento e análise de dados. Objetivou-se formar estudantes para produzirem informações atuando politicamente sobre problemas encontrados por eles no contexto escolar. A questão que conduziu a pesquisa foi: Como preparar estudantes para compreender conceitos estatísticos e produzir informações, ao invés de apenas consumilas? A pesquisa envolveu dois alunos do ensino médio (Pibic-Jr) e os encontros foram videogravados de modo a produzir dados para a análise e comunicação. Os resultados mostram que ensinar Estatística a partir de uma ação política contribui para que os estudantes desenvolvam habilidades que não se restringem a leitura dos dados.

Palavras-chave: Educação Estatística. Pibic Jr. Investigação-ação. Insubordinação criativa.

\section{Abstract}

Creative insubordination are political acts which occur when it breaks with pre-established rules, aiming to make progress and changes in society with a focus on social justice. This paper focus to report a research project that sought new approaches to teaching Statistics, through inquiry activities, exploration, data treatment and data analysis. Students were stimulated to produce information by acting politically on problems encountered by them in the school context. The question that led this research was: how to prepare students to understand statistical concepts and produce information, rather than just consuming it? The research involved two high school students (Pibic-Jr) and data was videotaped from the material produced by the students during meetings. The results show that teaching statistics from political action could help students develop skills that goes beyond literacy.

Keywords: Teaching Statistics. Pibic Jr. Action Research. Creative Insubordination.

\section{Introdução}

Estatística é a ciência que produz informações por meio de coleta, análise e interpretação de dados. Esse processo pode se dar de forma empírica ou por meio de 
simulações computacionais, tendo por base a observação de um fenômeno. Devido a sua característica de auxiliar a compreender a natureza de determinados fenômenos, com busca na generalização, a Estatística se relaciona com a Matemática, o que a torna uma ferramenta fundamental para agrupar, organizar, tabular, medir comportamentos das variáveis e quantificar dados para tomada de decisões. No entanto, a análise de dados não se baseia somente nos fundamentos matemáticos. Conduzir estudos estatísticos vai muito além de analisar números: envolve também analisar contextos, fenômenos, relações sociais, ações políticas; relacionar múltiplas variáveis; lidar com a incerteza; questionar; comunicar; e ter flexibilidade para modificar seu próprio ponto de vista e hipóteses.

As ações de insubordinação criativa são atos políticos que, de acordo com D'Ambrosio e Lopes (2015), ocorrem quando se rompe com regras preestabelecidas, visando obter progresso e mudanças na sociedade com foco na justiça social. Nessa perspectiva, no âmbito educacional, professores e professores-pesquisadores que atuam com essa postura agem de maneira a priorizar o aprendizado de seus alunos, imaginando, planejando, discutindo e implementando novas possibilidades de ensino. Este texto visa relatar um projeto de pesquisa que buscou o desenvolvimento de novas abordagens para o ensino de Estatística, por meio de atividades de investigação, exploração, tratamento e análise de dados, ao mesmo tempo que fornecia ferramentas para estudantes agirem politicamente dentro das escolas. A questão que conduziu a pesquisa foi: como preparar estudantes para compreender conceitos estatísticos e produzir informações, ao invés de apenas consumi-las?

Em busca de respostas para essa pergunta, conduzimos uma formação de um ano, com encontros quinzenais de aproximadamente duas horas, que envolveram dois alunos do Ensino Médio com bolsas de estudo do edital PIBIC-JR CNPQ. Para fins de pesquisa, a coleta de dados deu-se por videogravação de entrevistas e das atividades desenvolvidas na formação, fotografia dos cadernos dos alunos, arquivos produzidos por eles em softwares específicos, relatórios semanais dos encontros e materiais produzidos pelos alunos durante o planejamento e a execução de um projeto planejado e aplicado por eles na escola em que estudavam.

A aprendizagem nesse contexto foi construída de maneira dialética, com o pesquisador estimulando o raciocínio e a verbalização dos alunos por meio de perguntas durante a interação. Neste artigo, discutiremos o conceito de insubordinação criativa, ao narrar o processo metodológico da pesquisa e a atuação dos alunos. Os estudantes apropriaram-se de ferramentas Estatísticas, definiram um tópico de pesquisa, planejaram ações e organizaram informações para conscientizar a comunidade escolar e o diretor da escola sobre um problema local.

\section{Gráficos e tabelas como ferramentas de veiculação de informação}

Criar gráficos e tabelas com a ajuda dos recursos tecnológicos nos dias de hoje pode ser encarado como uma tarefa fácil, devido à possibilidade de transitar entre as diferentes representações com apenas um clique. Para ser considerado alfabetizado estatisticamente, é necessário mais do que saber criar gráficos e tabelas, é preciso saber ler, analisar e compreender o que os dados resumidos têm a nos contar. Ser letrado vai 
além: é preciso ser capaz de utilizar diferentes ferramentas escritas. Por essa razão, entendemos que uma educação emancipatória, crítica e política deve ter foco no letramento. E a Estatística é uma das ferramentas necessárias para o letramento.

Friel, Cursio e Bright (2001) afirmam que os educadores têm muito a aprender sobre os processos envolvidos na leitura, na análise e na interpretação de informações apresentadas estatisticamente. Por isso, ainda é preciso um quadro teórico geral que ajude a compreender representações gráficas, e é necessário investigar e considerar como esse conhecimento pode ser desenvolvido na prática docente e também nas pesquisas.

Coutinho, Silva e Almouloud (2011) apontam que os professores, ao descreverem as principais características dos dados, têm dificuldades em identificar os diferentes tipos de variáveis, pois confundem variáveis discretas e contínuas. Para a representação gráfica, compreender essa diferença pode ajudar bastante, pois, "[...] ao reduzir os dados, passando de casos individuais para valores de uma variável e suas respectivas frequências, introduz-se a distribuição de frequências, conceito complexo, que se refere ao agregado (população ou amostra) e não aos dados particulares" (ARTEAGA et al., 2009, p. 101).

Ocorre que diferentes tipos de gráficos podem representar diferentes objetos matemáticos, como frequências absolutas, relativas, acumuladas; porcentagens; médias; e dados discretos. No entanto, em alguns casos existem gráficos que são mais adequados para o que se pretende comunicar. $O$ que aflige o professor é a decisão acerca de qual gráfico é o mais adequado a representação que se deseja construir para qual tipo de variável. Entendemos que fazer transições entre diferentes representações é extremamente importante durante o processo de aprendizagem, e devemos fazer isso, ao vincular a aprendizagem aos contextos dos dados (HENRIQUES; OLIVEIRA, 2012). Além disso, é necessário ajudar o aluno a compreender como as variáveis se comportam em diferentes tipos de representações. A pergunta que deve conduzir o trabalho docente nesse sentido seria: o que essas variáveis têm a nos dizer e sobre quem?

De acordo com Pfannkuch, Regan e Wild (2010), o desenvolvimento de habilidades para contar histórias estatísticas é desafiado pelas práticas atuais de ensino. Isso ocorre porque, durante o processo de ensino, deve haver um debate aberto sobre o que constitui uma boa verbalização embasada na estrutura de gráficos e tabelas. Os professores precisam estar atentos a quais conceitos deveriam ser trazidos para a atenção dos estudantes e à forma como fazê-lo. Isso inclui atentar à linguagem, invocar pensamentos descritivos e inferenciais, compreender o contexto, delimitar a abrangência da situação estudada, determinar informalmente se as alegações podem ser feitas sobre as populações a partir dos dados da amostra e raciocinar por diferentes prismas, questionando suas próprias afirmações.

É preciso ajudar os estudantes a melhorar suas habilidades de relacionar informações; suas capacidades de filtrá-las e de extrair significados; e, por último, sua capacidade comunicativa. Na maior parte das vezes, a atenção no trabalho pedagógico, fica concentrada na capacidade técnica dos estudantes, porém acreditamos ser possível desenvolver concomitantemente a capacidade comunicativa. Fazer isso é de extrema importância para a emancipação política e a formação da consciência dos sujeitos. É uma 
forma de ajudar a construir uma sociedade mais crítica e participativa. Nesse sentido, a Educação Estatística pode ser de grande ajuda.

\section{O conceito de insubordinação criativa e a sua relação com projetos de Educação Estatística}

A população, de maneira geral, tem pouca participação na elaboração, na decisão e na implementação de políticas públicas. Normalmente, os cidadãos não as compreendem em profundidade e têm dificuldade de fazer uma análise crítica dos objetivos, das crenças, dos valores e dos dados que embasam tais políticas. O primeiro contato dos cidadãos com a execução das políticas ocorre durante a interação com agentes públicos. Lipsky (1971) relata que, no contexto americano, policiais, professores, assistentes sociais e outros profissionais são acusados de serem insensíveis, despreparados para trabalhar com comunidades periféricas, resistentes a mudanças e racistas.

No contexto brasileiro podemos acrescentar críticas que vão além. Há um consenso, principalmente nas periferias, de que os agentes públicos tradicionalmente agem como um braço do estado, muitas vezes sendo opressores, normatizadores, autoritários e inertes diante das particularidades dos sujeitos que necessitam dos seus serviços.

De acordo com Lipsky (1971), as acusações das populações mais carentes são transferidas pelos agentes ao elevado nível de burocracia ao qual são submetidos. Apontam-se a falta de condições adequadas de trabalho, a falta de pessoal na ativa, uma demanda muito grande de pessoas para serem atendidas e os baixos salários. E, no caso específico dos profissionais da Educação: salas de aulas lotadas, a angústia diante da possibilidade de perder a autoridade, a indisciplina que pode ser causada pela inabilidade ao gerenciar uma turma e a pressão que proveniente das expectativas dos colegas de trabalho, dos superiores e do público em geral. Esses problemas atingem principalmente - mas não apenas - os profissionais novatos.

Estar diante de tais circunstâncias descritas força os profissionais da Educação a enfrentar situações em que precisam tomar decisões rápidas, sem planejamento, sem informações sobre os sujeitos envolvidos, sobre o contexto ou sobre a causa dos conflitos, de modo que não lhes é possível compreender as demandas em profundidade ou analisar os méritos das suas decisões. Ao tomar decisões nessas condições, dificilmente irão atender às expectativas.

De acordo Lipsky (1971), uma característica comum do comportamento organizacional laboral é que os indivíduos desenvolvam simplificações ou algum tipo de resposta objetiva e padronizada, escrita ou falada, que lhes permita tomar decisões de forma rápida e eficiente. Um exemplo de resposta simplificada é quando um educador define se um aluno é bom ou problemático segundo aparência, cor, vestimenta, histórico familiar, gênero ou status social. Outro exemplo de resposta simplificada ocorre quando o professor planeja como apresentar um novo conteúdo de modo que a sistematização não gere desordem. Em todos os casos, ações simplificadas tornam-se problemáticas e causam prejuízo às relações, principalmente quando partem do senso comum ou quando são fundamentadas em situações de desigualdade, estereótipos, preconceitos, rótulos, 
modelos ou trivialidades construídas socialmente ou culturalmente. Tais circunstâncias, via de regra, compõem o cenário das escolas em que atuam profissionais com pouco preparo para contrapor-se a elas, para insubordinar-se.

A insubordinação criativa, de acordo com D’Ambrosio e Lopes (2015), é um conceito que surgiu em 1981, quando Morris et al. publicaram um estudo etnográfico realizado com diretores de escolas americanas que utilizavam estratégias não usuais para romper com a burocracia e adaptar políticas públicas em prol de um melhor atendimento às necessidades da comunidade local. Havia um entendimento de que a padronização das políticas engessava as ações na escola, enquanto o excesso de tentativas de aprimoramento seria desorientador e contraproducente.

Para compreender o conceito de insubordinação criativa, é preciso primeiro partir da premissa de que esse conceito não considera a ideia única de desobediência segundo o senso comum. A insubordinação criativa se dá na interação do profissional que presta serviço público com a população, ao enfrentar estereótipos e fundamentações preconcebidas. A insubordinação criativa é um componente da tomada de decisão discricionária (HAYNES; LICATA, 1995) pelo profissional, a qual, segundo esses autores, se distingue do ato administrativo vinculado.

De acordo com Göttems (2012), os atos administrativos vinculados são aqueles para os quais o agente público é legitimado e cuja execução é de sua responsabilidade, independentemente do seu nível hierárquico. Nesse caso, o agente tem descrito na lei os requisitos e as condições da execução do ato. Para esses atos, há uma imposição legislativa que absorve, quase por completo, a liberdade de decisão do agente. Possivelmente um agente público responsável não deixará de atuar na legalidade, nem seria isso o que a sociedade espera dele. Diferentemente, os atos discricionários são aqueles que os agentes públicos podem praticar com liberdade, ou seja, fazem a escolha do seu conteúdo, de seu destinatário, de sua conveniência, de sua oportunidade e do modo de sua realização. Isso não significa a inexistência de lei, mas a lei permite ao agente que a prática do ato se dê pela maneira e nas condições que sejam mais convenientes ao interesse público.

Os atos discricionários seguem uma ordem hierárquica do nível mais alto para o mais baixo da cadeia. A compreensão dos atos nos níveis subalternos se dá por uma interpretação política. Nos níveis mais altos da hierarquia as decisões são tomadas olhando para um contexto macro; nesse caso, é preciso um mínimo de padronização para atender aos sujeitos beneficiários. Nos níveis mais baixos da hierarquia, é necessária flexibilização da padronização, isso porque nesse nível há um olhar para os microambientes, para os indivíduos ou para os grupos separadamente. Torna-se óbvio que esse fluxo de decisões causará problemas para os grupos minoritários ou marginalizados, se não houver uma interpretação com olhar individual para os contextos e para as condições histórico-sociais da população atendida nos níveis mais baixos da hierarquia.

O ato discricionário, por um lado, permite que o agente público tome decisões administrativas com liberdade. Por outro, quando essas decisões não se pautam em valores de solidariedade e justiça social, podemos ter indícios de opressão ou dominância 
por parte do sujeito legitimado para a função de executar o ato. Isso acaba por gerar conflitos ou inutilidade do serviço prestado.

Segundo Gutiérrez (2009), pesquisadora que discute o conceito de insubordinação criativa no contexto da Educação Matemática, qualquer esforço para tentar definir democracia e equidade irá começar por uma questão: quem decide o que será colocado nas categorias? Nessa busca por respostas, é possível que a definição seja inalcançável, pois, ao tentar definir democracia e equidade no contexto educacional, corre-se o risco de criar novas relações de poder, assim como acontece com o conceito de insubordinação criativa.

De acordo com Gutiérrez (2013), ensinar Matemática não é uma atividade política neutra. D’Ambrosio e Lopes (2015) afirmam que, no ensino da Matemática, as ações de insubordinações criativas são identificadas quando o professor decide: romper com os discursos generalizadores; analisar os resultados dos estudantes como objeto para melhorar a aprendizagem, desprezando ferramentas de quantificação de habilidades; argumentar para explicar as diferenças de aproveitamento dos alunos, usando discursos fora dos padrões de simplificação; questionar as formas como a Matemática é culturalmente apresentada na escola; enfatizar a incerteza da disciplina de Matemática e sua construção histórico-cultural; posicionar os alunos como autores da Matemática; e desafiar os discursos discriminatórios sobre os alunos.

A Matemática é uma ferramenta poderosa do mundo capitalista, porque fundamenta informações de vários setores do mercado de capitais, da produção, de recursos e outras sobre quaisquer atividades humanas. É por isso que a Matemática transmite status na sociedade, o que, de acordo com Gutiérrez (2013), deveria nos levar a ser mais conscientes sobre o que pedimos para os alunos fazerem durante as aulas. De fato, muitos professores (e pesquisadores) reproduzem modelos de ensino autoritários, repugnam o papel político de sua função e daquela que a Matemática exerce na sociedade. Esses profissionais são pouco conscientes de sua incumbência e tornam-se cúmplices da reprodução da Matemática como forma de microagressão.

Gutiérrez (2013) também argumenta que todo o ensino da Matemática é um ato político, porque professores de Matemática trabalham identidades, mesmo ao considerarem que não. A contribuição sobre a identidade dos alunos ocorre quando os professores reproduzem o que a Matemática é, dando ênfase à forma como as pessoas poderiam se relacionar com ela (ou não). A relação que pretendemos estabelecer nesse texto entre a insubordinação criativa e a Educação Estatística visa desmistificar a passividade política do ensino de Matemática. Entendemos que essa possa ser uma ferramenta poderosa para ajudar crianças e adolescentes a produzirem informações para resolver problemas do seu próprio contexto, argumentando e comunicando sobre eles.

Nesta pesquisa envolvemos em uma formação de um ano dois estudantes do Ensino Médio. Inicialmente procuramos formá-los em um ambiente que os levassem a fazer perguntas ao invés de dar respostas rápidas e simplificadas. Até então, o foco da investigação estava no processo de aprendizagem e no raciocínio empregados por eles ao fazer Estatística. Ao longo dos encontros, ao adentrar na perspectiva de ensino por meio de projetos, vimos a possibilidade de dar ênfase a formação política dos estudantes com foco no bem-estar e na justiça social. Embora a pergunta inicial não tenha sido 
reconfigurada, sentiu-se a necessidade de estudar referenciais teóricos que permitissem comunicar essa nova construção. Na próxima secção descreveremos o processo metodológico empregado nesse contexto.

\section{Metodologia}

No centro do redemoinho dialético no âmbito educacional, quando orientado por uma prática reflexiva, a figura do professor possui privilégios. Ao planejar, agir, analisar, observar e avaliar situações decorrentes do ato educativo torna-se possível que o docente se reinvente, ao refletir sobre suas próprias ações e fazer delas berços de teorias que estabelecem diálogos entre o pensar e o agir (COUTINHO et al., 2009).

Durante $\mathrm{o}$ ato educativo, nas respostas aos sujeitos com quem dialoga, são forjadas as abordagens docentes que se tornarão mais efetivas na busca da aprendizagem. Ainda há um segundo momento de reflexão. Esse ocorre após o ato educativo, quando o professor se debruça para rever suas abordagens, analisar os atos e as respostas dos sujeitos com quem se envolveu. Por último, o que torna esse professor investigador é a virtude de contribuir para o aperfeiçoamento ou as mudanças das práticas educacionais, ao tentar compreender as respostas dadas a sua ação educativa.

No projeto de pesquisa desenvolvido que subsidia a escrita desse artigo, seguimos a orientação metodológica a investigação ação, pela qual foram elaboradas propostas de ensino com foco na Estatística descritiva. É muito importante encontrar meios de ensinar Estatística para adolescentes e crianças, que superem as crenças errôneas provenientes de uma educação que incida somente sobre competências técnicas. Permitir que alunos realizem análises exploratórias dos dados, conduzindo-os para criar representações a partir dos seus contextos e conhecimentos prévios, leva-os a reorganizar seus próprios conceitos estatísticos e a tomar consciência de seu papel político na sociedade.

Com o objetivo de preparar alunos do Ensino Médio para desenvolver estudos estatísticos que os ajudassem a identificar e compreender mitos, crenças e verdades relacionados a problemas sociais, dois alunos do 2. ano de uma escola pública foram contatados por meio do programa PIBIC-JR CNPQ. Durante um ano eles receberam bolsas de estudo para participar de uma formação que culminaria em um projeto de pesquisa cuja temática seria escolhida por eles.

Os trabalhos de formação foram conduzidos pelo autor deste texto, com foco em uma intencionalidade emancipatória dos estudantes, via o reconhecimento da dimensão política da educação e da investigação educacional. Os pressupostos levam em consideração a interação de pessoas no momento em que aprendem e ensinam, ao se debruçarem sobre suas realidades concretas, com a intenção de compreendê-las e transformá-las (GRABAUSKA; BASTOS, 1998).

O planejamento das atividades desenvolvidas teve por foco compreender pontos específicos de abordagens de ensino da Estatística; no entanto, foi escolhida para desenvolvê-las uma dinâmica flexível, com base no diálogo e em indagações que reorientavam as ações. A análise se deu sobre o raciocínio empregado e sobre os materiais produzidos pelos alunos enquanto executavam as tarefas e respondiam às indagações. Os dados foram coletados por meio de videogravação dos encontros, reflexão escrita dos alunos e imagens do material produzido nos cadernos e nos 
softwares. Utilizamos na formação os softwares Excel e Fathom, para que os alunos construíssem tabelas e gráficos, ao transitar entre diferentes representações.

\section{O contexto dos estudantes e o que a Estatística representava}

Participaram da pesquisa dois alunos, uma menina e um menino, respectivamente de 16 e 19 anos de idade, que foram indicados para participar do projeto por serem considerados pela escola alunos com bom rendimento. Utilizaremos nomes fictícios, Andreia e Ronaldo, para preservar a identidade dos alunos. Ambos começaram a pesquisa como alunos do 2..$^{\circ}$ ano do Ensino Médio de uma escola pública do município de Ituiutaba, no interior de Minas Gerais, na região do Triângulo Mineiro. Como o projeto durou um ano, ao final cursavam o $3 . \stackrel{\circ}{\text { ano. }}$

Durante o ano em que desenvolvemos a pesquisa, pudemos constatar dedicação e pontualidade por parte dos alunos: não se ausentaram em nenhum dos encontros agendados e entregaram as atividades solicitadas nas datas combinadas. Seus afazeres não se limitavam à escola, pois, além de estudarem pela manhã, ambos eram alunos de cursos profissionalizantes no SENAI. O aluno Ronaldo ainda trabalhava fazendo serviços de garçom aos finais de semana em restaurantes da região. Devido às dificuldades socioeconômicas de ambos e à alta demanda de atividades dos estudantes, nossos encontros aconteciam quinzenalmente no período noturno, às vezes no sábado e nas férias escolares. Tivemos uma agenda flexível, para não atrapalhar os afazeres rotineiros dos estudantes. Nos seis meses finais, conseguimos aumentar a frequência dos encontros para semanais. Ambos os estudantes foram remunerados com uma bolsa de aproximadamente 200 reais mensais, o que parecia ser de grande ajuda para o orçamento familiar.

Começamos o primeiro encontro questionando-os sobre o que eles achavam que era Estatística e se já a tinham estudado. Ambos a princípio disseram não ter uma definição do que seria Estatística. Explicamos então que não precisavam dar uma definição formal, apenas que dissessem sobre o que achavam que seria. Andreia relacionou Estatística com gráficos, lembrou que estudou algo sobre isso no curso profissionalizante. Depois, Ronaldo lembrou que estudou sobre gráficos na escola, nas disciplinas de Matemática e Geografia. Relatou que em Geografia via-os mais com enfoque sobre a intepretação, em Matemática sobre construção e cálculos. Quando questionado sobre que tipo de gráficos era produzido na disciplina de Matemática, Ronaldo fez menção ao conteúdo de funções.

Andreia ponderou que esse tipo de gráfico não teria relação com Estatística, trouxe como exemplo gráficos de barras e linhas e não soube apontar outros. Ao finalizar essa conversa, ambos disseram que costumam ter acesso aos gráficos normalmente na disciplina de Geografia, mas somente com uma abordagem sobre a interpretação. Ronaldo relatou:

Na verdade, na Matemática a gente constrói os gráficos não da Estatística, mas aqueles de funções. Quando entra na Estatística a gente trabalha mais com interpretação e tem por base os cálculos. A gente não constrói gráficos.... Não lembro de ter coletado dados, estudado os dados para depois ter montado os gráficos com base nos estudos (videogravação, 22 set. 2016) 
Andreia se lembrou de ter feito uma vez uma pesquisa. Segundo ela, não era aula de Matemática. Sua turma passou nas salas coletando algumas informações e depois construíram um gráfico. Isso ocorreu no 1. ano do Ensino Médio. Questionada sobre em qual disciplina havia feito a pesquisa, respondeu: "Matemática!" (risos). Ou seja, Andreia não considerava que esse tipo de pesquisa fosse uma aula de Matemática. Disse ainda que, depois de terem construído os gráficos, não tiveram retorno da professora. No final, tanto Andreia quanto Ronaldo disseram nunca terem utilizado o Excel ou qualquer outro recurso para construir gráficos e tampouco os conheciam.

\section{Levantando os conhecimentos prévios para construção cognitiva de novos conceitos}

Ainda no primeiro encontro tínhamos por objetivo que os alunos compreendessem os conceitos de indivíduo, amostra, população e variável. Por experiência, ao longo dos anos desenvolvendo atividades de pesquisa em Educação Estatística, tínhamos por pressuposto que os estudantes, ao serem convidados para representar informações sobre seus dados, utilizariam aqueles gráficos que são mais comuns para eles. Nesse caso, mesmo que recursos tecnológicos fossem disponibilizados, acreditávamos que sua exploração ficaria limitada ao uso de gráfico de linhas, colunas ou barras e, talvez, de setores. Ao fazer isso, provavelmente os estudantes não refletiriam sobre os conceitos supracitados e por consequência não utilizariam as ferramentas mais adequadas para comunicar-se. Era preciso apresentar novas ferramentas de análise e criar situações em que eles fossem confrontados cognitivamente, refletindo sobre sua própria produção de informações.

Também enxergamos ser de extrema importância, quando se faz pesquisa e ensina Estatística, levar os alunos a construir projetos que lhes oportunizem refletir sobre temáticas que os afligem. Todavia, temos observado que as pesquisas que têm por foco refletir sobre atividades de projetos em sala de aula costumam começar pela escolha de um tópico, seja por parte do docente ou do aluno. Para esta pesquisa entendemos que poderia ser mais interessante, se primeiramente expuséssemos os estudantes a novas ferramentas, para culminar em um projeto ao longo do processo. Na nossa compreensão, proceder dessa forma os ajudaria a fortalecer sua autonomia para aprofundarem suas ações em uma investigação. Invertemos, portanto, a ordem do trabalho com projetos, deixando a escolha do tópico para o segundo semestre.

Primeiramente, foi explicado aos estudantes como ocorreria a dinâmica durante o ano letivo. Depois Ihes foram apresentadas as palavras "indivíduo", "amostra", "população" e "variável". Enquanto eles verbalizavam suas reflexões, perguntas lhes eram feitas com o objetivo de levá-los a desconstruir ideias iniciais, refletir e estreitar a compreensão sobre esses conceitos. A proposta era que, ao final, conseguissem identificar, a partir de uma tabela, cada um dos seus componentes. $E$ que também apontassem as variáveis, elencando suas características e separando-as por categorias (discretas, categóricas e contínuas). Essa identificação seria importante para que pudessem selecionar os gráficos mais adequados a cada uma das situações.

Para os estudantes houve uma confusão cognitiva muito grande, principalmente ao tentar exemplificar os conceitos de indivíduo, amostra e população. Suas inquisições ao 
comparar os conceitos os levavam a conjecturar de forma que os argumentos se sobrepunham: a amostra era ora um indivíduo, ora uma população. Acreditávamos que essa confusão seria causada pela falta de um contexto específico para se embasarem. Um exemplo dado por Ronaldo foi: "O sangue de um indivíduo tipo A negativo pode ser uma amostra". Isso poderia ser verdade ou não. O sangue coletado para análise poderia ser um ou outro, a depender de se seria feita uma análise da situação patológica de um único sujeito ou se a ideia fosse verificar características em comum dos sujeitos que possuem o mesmo tipo de sangue. Portanto, para definir se a porção de alguma coisa seria indivíduo ou amostra, teríamos que adentrar ao contexto do que seria investigado, analisando as perguntas feitas.

Supúnhamos que, para iniciar um estudo investigativo em Estatística com estudantes do Ensino Médio, fosse viável partir da definição informal dos conceitos, atrelando-os a um contexto próximo da realidade deles. Deixamos os estudantes livres para fazer construções cognitivas, estimulando-os a refletir sobre suas afirmações. Para ajudá-los, poderia ser mais palpável analisar e construir os conceitos sobre tabelas. Fizemos isso após nossa discussão inicial. Solicitamos que analisassem a Tabela 1 e identificassem nela os elementos que a compunham. Mesmo ao analisar a tabela, tiveram dificuldades para identificar que todos os espécimes compunham uma amostra. Para eles, cada espécime era uma amostra, ao mesmo tempo que também era um indivíduo; e a composição de todas os espécimes da tabela formavam uma população.

Tabela 1: Exemplo de uma planilha apresentada por um botânico

\begin{tabular}{|c|c|c|c|}
\hline $\begin{array}{c}\text { ID } \\
\text { Espécime }\end{array}$ & $\begin{array}{c}\text { Comprimento } \\
\text { do Caule } \\
\text { (cm) }\end{array}$ & $\begin{array}{c}\text { Número de } \\
\text { pétalas da } \\
\text { flor }\end{array}$ & Cor da flor \\
\hline 1 & 3,1 & 28 & Amarela \\
\hline 2 & 2,6 & 5 & Branca \\
\hline 3 & 8,2 & 8 & Vermelha \\
\hline 4 & 5,9 & 12 & Rosa \\
\hline 5 & 14,7 & 5 & Amarela \\
\hline
\end{tabular}

Fonte: Baldi e Moore (2014, p. 6 )

Continuamos a conversa, avançando para o conceito de variável. Questionamos o que entendiam por variável. Andréia deu exemplos de densidade demográfica.

\footnotetext{
Andréia: Existem lugares em nossa cidade que é mais habitado e outros não são tão habitados, ou seja, a população é menos variável. É algo que aumenta ou diminui.

Ronaldo: O crescimento de alguém seria uma variável? (E afirmou): Por exemplo, quando muda o tempo, algo cresce mais, quer dizer, varia. Quero dizer que duas coisas em tempos iguais crescem diferentemente.
}

Todos os outros exemplos dados por ambos mostravam que entendiam que variáveis estavam atreladas a termos quantitativos e especificamente a algo que aumenta ou diminui. Outras variáveis, como as variáveis categóricas, foram desprezadas pelos estudantes.

Entendemos que seria necessário auxiliar os estudantes para que compreendessem que as variáveis, no caso da Estatística, poderiam estar relacionadas 
com alguma característica do objeto em estudo ou com alguma resposta do objeto a um estímulo (no caso, uma atividade empírica). Ou seja, podemos medir, contar e observar características ou estimular uma ação com intuito de observar suas consequências. $A$ compreensão de conceitos de variável parece não ser tão trivial para os estudantes, o que corrobora a afirmação de Coutinho, Silva e Almouloud (2011) sobre a dificuldade também dos professores.

Algumas vezes, as características do objeto são quantificáveis para um indivíduo, mas outras, não. No caso da amostra, quando não é possível quantificar as características do objeto em estudo, pode-se agrupá-las e contá-las para compreender melhor a situação. Nesse caso, pode-se confundir variável discreta com categórica; por isso é preciso cuidado ao construir esses conceitos.

Ao entregar a Tabela 1, insistimos para que os estudantes dissessem onde poderiam encontrar os indivíduos, a amostra, a população e as variáveis.

\footnotetext{
Andreia: Podemos identificar um indivíduo aqui, a cor é um indivíduo.

Ronaldo: O comprimento do caule poderia ser uma variável?

Pesquisador: Haveria mais alguma variável?

Andreia (refletindo que o número de pétalas também era uma variável): $A$ cor das flores também varia.

Pesquisador: As variáveis não deveriam ser apresentadas no formato numérico? Andreia: Não! Pode ser cor também, por exemplo: uma violeta pode ser branca, roxa, azul... Depende de qual tipo de violeta.

Pesquisador: Vocês estão defendendo um ponto de vista diferente do anterior... Ronaldo (risos): Então variável é algo que muda, como cor, por exemplo.
}

Voltamos a questionar qual seria a amostra. Ronaldo afirmou que a amostra seria o ID espécime da planta e que a amostra seria de cinco plantas. Andreia continuou dizendo que cada planta era um indivíduo, e a população seria o conjunto de todas as plantas. Levamos os estudantes a refletir se estávamos falando de todas as plantas ou se haveria alguma característica em comum àquelas plantas. Andreia respondeu: "Parece que todas as plantas têm flores".

Continuamos a conversa, até que percebessem que, dentro de um estudo estatístico, estamos procurando características que uma população possui em comum. Depois de fazer isso, procuramos estimular os estudantes a perceber as diferenças entre as variáveis. Por meio do diálogo, nós os ajudamos a identificar na Tabela 1 a variável discreta, a contínua e a categórica, o que parece ter ficado claro para eles.

\section{Um exemplo das atividades iniciais com gráficos e tabelas}

Prosseguimos os encontros, apresentando aos estudantes diferentes tipos de gráficos. Mostramos em uma folha de papel A4 gráficos - de linhas, colunas, setores, histograma, dispersão, de pontos, box-plot e diagrama de ramo e folhas - sem títulos, sem variáveis e sem legendas. Dos gráficos apresentados, os estudantes reconheceram apenas os quatro primeiros. Para eles não havia diferença, a não ser visual, entre o histograma e o gráfico de colunas. Ao ser questionado, Ronaldo respondeu que os dois gráficos se chamavam gráficos de barras e ponderou que a única diferença era que no histograma as colunas estavam juntas e no gráfico de colunas, não. Nos encontros 
seguintes fizemos um grande esforço para que ambos relacionassem o histograma ao agrupamento de dados de uma variável contínua.

Depois de apresentar os gráficos, buscamos conduzir a pesquisa de modo que os estudantes pudessem aplicar os novos conceitos construídos por eles. A ideia era que pudessem, por meio da exploração de tabelas, compreender qual gráfico seria mais adequado para que tipo específico de variável. Começamos pelo gráfico de setores. Perguntamos qual tipo de variável seria mais adequado para ser usado naquele gráfico. Ronaldo respondeu imediatamente que seria a variável discreta e justificou que costumava observar que, naquele tipo de gráfico, os valores são apresentados em porcentagem. Andreia confirmou que havia feito a mesma observação. A nossa hipótese inicial era que os estudantes já tivessem interpretado esse tipo de gráfico, ao contabilizar porcentagens. No entanto, acreditávamos que eles ainda não tinham ideia de que a soma das categorias individuais deveria representar o total da amostra coletada de uma população. Ou seja, queríamos que percebessem que poderiam utilizar o gráfico de setores para representar variáveis discretas, contínuas ou categóricas. E que notassem que o gráfico de setores é mais adequado, quando se quer comparar a relação de cada categoria com o todo.

Levamos em consideração a possibilidade de que nunca tivessem construído esse tipo de gráfico, pois haviam relatado anteriormente que nunca haviam utilizado recursos tecnológicos nas aulas de Matemática. Construir o gráfico de setores manualmente pode parecer simples; todavia, na prática, a construção requer o uso de algumas ferramentas (régua, compasso e transferidor) e conceitos de geometria. Por essa razão, supusemos que seus professores nunca houvessem trabalhado com a construção desse tipo de gráfico. Essa hipótese foi confirmada posteriormente. Pedimos que fizessem um rascunho do gráfico a partir da Tabela 2. Ronaldo prontamente respondeu: "Isso daqui não é difícil".

Tabela 2: Cigarros nos Estados Unidos em 2006

\begin{tabular}{|c|c|}
\hline Grupo & $\begin{array}{c}\text { Percentual de } \\
\text { Fumantes }\end{array}$ \\
\hline Homens 18-24 anos & $28,50 \%$ \\
\hline Mulheres 18-24 anos & $19,30 \%$ \\
\hline Homens 25-29 anos & $28,90 \%$ \\
\hline Mulheres 25-29 anos & $23,30 \%$ \\
\hline
\end{tabular}

Fonte: Baldi e Moore (2014, p.12)

Enquanto Andreia rascunhava, parecia inquieta. Questionamos o porquê de sua inquietação. Ela disse que estava verificando se as porcentagens somavam $100 \%$ e enfatizou que toda a amostra deveria somar $100 \%$. No caso de Ronaldo, percebemos que o seu rascunho não respeitava escalas e proporções, e o seu gráfico estava dividido em quatro partes iguais, conforme mostra a Figura 1. Perguntamos por que os gráficos dos dois estudantes estavam diferentes. Ronaldo respondeu que era difícil encontrar exatamente a proporção de cada setor, Andreia concordou. Pela conversa ficou nítido que naquele momento, sem ajuda, nenhum dos dois conseguiria construir adequadamente 0 gráfico. Um dos motivos é que não tinham ferramentas para fazê-lo e, tampouco, sabiam utilizar o software Excel. 
Figura 1: À esquerda, gráfico produzido por Andreia; à direita e no centro, por Ronaldo

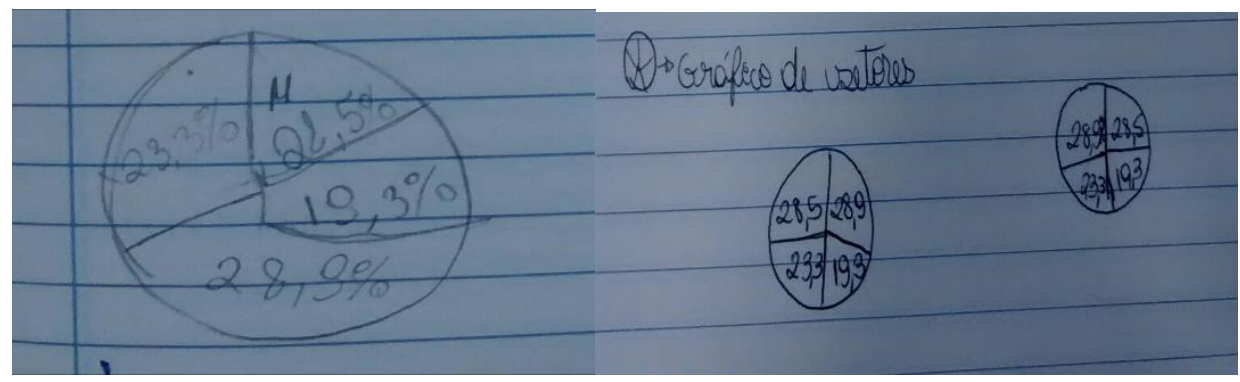

Fonte: Arquivo do pesquisador

Para resolver esse problema, convidamos ambos a construírem o gráfico, utilizando o Excel. Como era a primeira vez que faziam isso, fomos auxiliando a construção, explicando os caminhos. Ao terminarem, foram questionados sobre quem seria a população descrita na Tabela 2 . Andreia respondeu prontamente que a população seria pessoas fumantes, contudo, a população seria, na verdade, de pessoas fumantes e não fumantes, de idades entre 18 e 29 anos. O nosso objetivo com essa pergunta e com as outras que vieram era ajudar os estudantes a perceber que o gráfico de setores não era adequado para representar os dados que compunham essa tabela. Após a afirmação de Andreia, perguntamos se todas as pessoas fumantes faziam parte da população. Ambos balançaram a cabeça negativamente. Andreia respondeu que seria só uma parte das pessoas fumantes, da faixa etária de 18 a 29 anos.

Continuamos perguntando se a população seria de todas as pessoas fumantes de 18 a 29 anos de idade. Eles confirmaram positivamente. Perguntamos então quem seria a amostra. Andreia elencou cada uma das categorias. Questionamos sobre quem seriam os indivíduos. Os estudantes ficaram em silêncio; haviam percebido que os indivíduos estavam agrupados dentro das categorias. Fizemos então uma discussão sobre isso. Por fim, solicitamos que construíssem um gráfico de colunas ao lado do gráfico de setores, conforme Figura 2. Quando terminaram, perguntamos se os gráficos traziam informações diferentes. Andreia relatou que eles traziam a mesma informação, mas de um jeito diferente; observou apenas que o gráfico de setores não trazia valores em porcentagem, enquanto $o$ de colunas, sim. Explicamos como deveriam proceder no software para que a porcentagem ficasse evidente no gráfico de setores. Depois que fizeram isso, durante 0 diálogo, continuaram afirmando que não havia diferença entre os gráficos.

Insistimos, pedindo que justificassem por que no gráfico de setores as cores eram diferentes. Ronaldo respondeu: "Acho que para diferenciar as categorias entre elas".

Depois de insistir com mais algumas perguntas, tivemos dificuldades de ajudar os estudantes a perceber que o gráfico de setores não era o mais adequado para aquela situação. Talvez esse entrave tenha sido consequência da proposta da pesquisa de conduzi-los de modo que suas respostas fossem pessoais. Tentávamos conduzir os diálogos, sempre que possível, por meio de perguntas, evitando dar respostas conclusivas.

Pedimos a eles que trabalhassem em mais duas tabelas, construindo seus respectivos gráficos, sendo um de setores e um de barras. Ambos perceberam que a soma percentual das categorias deveria dar $100 \%$. No entanto, não conseguiram 
perceber que, no gráfico de setores da Figura 2, não fazia sentido comparar as partes com o todo. Ocorria que nessa situação cada categoria individualmente representava uma parte do todo da sua própria categoria, não do total da população em análise. O fato de a soma dessas categorias ser $100 \%$ não lhes permitiu refletir sobre a amostra.

Figura 2: Gráfico produzido pelos estudantes

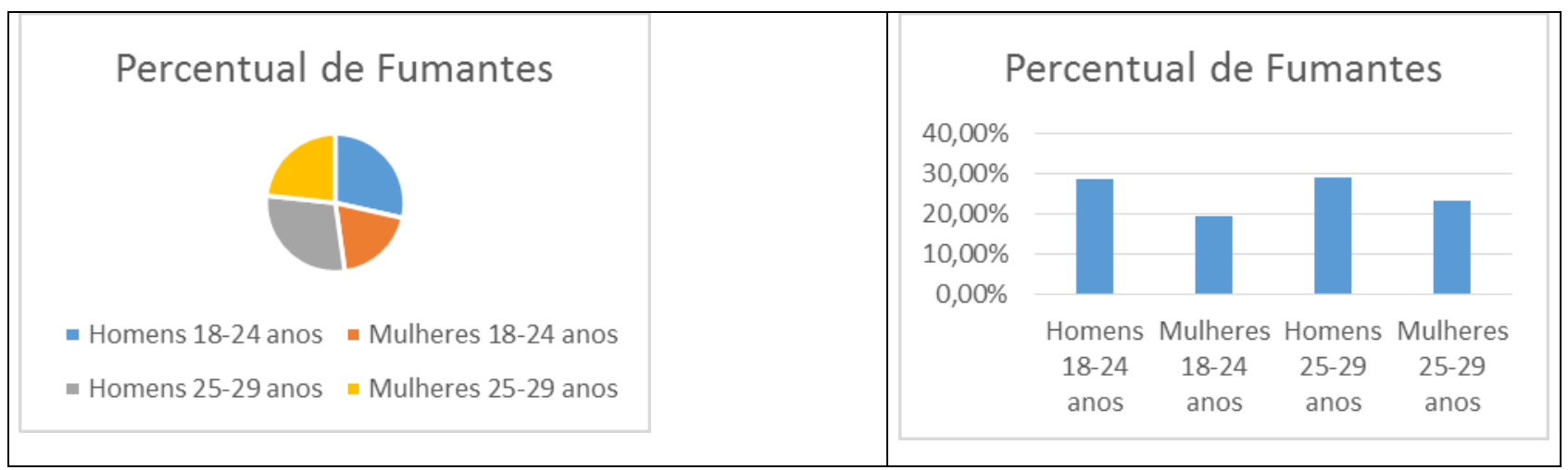

Fonte: Arquivo do pesquisador

Continuamos com os estudantes por mais quatro meses, apresentando tabelas e pedindo que identificassem os indivíduos, as amostras, as populações e as variáveis, separando-as por características. A cada atividade apresentada, solicitávamos que construíssem gráficos no software Excel e Fathom. Eles podiam fazer de livre escolha, interpretando os gráficos e contando o que era possível saber sobre os dados. A cada atividade, planejávamos perguntas que os levassem a necessitar de novas ferramentas para eles, como, por exemplo, gráfico de linhas, histograma e box-plot. Quando sentiam necessidade, apresentávamos uma nova ferramenta e discutíamos suas características. No caso de haver a possibilidade de utilizar diferentes ferramentas, íamos induzindo-os a apresentar os dados com diferentes representações. Ao final solicitávamos que nos dissessem que informações cada tipo de gráfico nos dava. Ao final dessa etapa, não tínhamos como objetivo quantificar o quanto os alunos aprenderam, mas deixá-los mais preparados para conduzir um processo de investigação. A avaliação se deu pelo processo, e não por momentos.

Um problema do contexto dos estudantes: o restaurante escolar, o desperdício de alimentos e a formação política

Depois de seis meses de formação, pedimos a Andreia e Ronaldo que escolhessem um tema de seu interesse para ser investigado. A temática deveria emergir de algum problema dentro da escola. Foi explicado que a princípio não pensaríamos em gráficos, tabelas e nem em Estatística. Exploraríamos a problemática para verificar se, ao final, poderíamos produzir algum tipo de informação. Explicamos que deveriam produzir um relatório sobre a problemática.

Os estudantes apontaram que um dos problemas na escola era a comida servida durante os intervalos. Andreia relatou que na última semana havia sido servida sopa todos os dias. Ronaldo concordou que esse é um problema, já que muitas pessoas reclamam do cardápio e, principalmente, da sopa. Perguntamos se conseguiriam produzir alguma informação sobre esse assunto. Ambos concordaram que seria um bom tema. Continuamos conversando sobre o assunto. Queríamos saber se eles achavam que havia 
desperdício de merenda. Eles confirmaram que havia desperdício. Ronaldo acreditava que, de cada 20 pessoas que se alimentavam, 5 pelo menos desperdiçavam comida. $E$ relatou ainda que, muitas vezes, os colegas nem jogavam a comida no lixo, deixavam o prato cheio em cima da mesa. Andreia confessou que não costumava comer no restaurante por duas razões: a fila para servir-se era muito grande, e a comida era apimentada demais para ela, uma característica regional. Ela achou que o tema seria bem interessante, pois acreditava que pudessem fazer uma pesquisa de satisfação, relacionar com o desperdício e saber por que as pessoas comem ou não comem merenda na escola. Solicitamos que fossem anotando o que gostariam de saber sobre a temática: desperdício, aceitação... Enquanto refletíamos, Andreia ponderou que achava interessante saber mais sobre as verbas que são recebidas pela escola para compra da merenda.

Questionamos se seria possível medir o desperdício. Ronaldo disse que não haveria problemas, deveriam ficar durante o intervalo observando e, ao final, para verificar, colocariam os restos em um saco plástico e depois em uma balança. Questionamos também sobre quem eles achavam que desperdiçava mais comida, os meninos ou as meninas. Ronaldo acreditava que eram os meninos. Andréia concordou e também disse que parecia que eles frequentavam mais o refeitório do que elas. Ronaldo discordou, pois acreditava que a frequência era igual. Para saber qual gênero desperdiçava mais, chegamos à conclusão de que seria necessário dividir os restos em baldes diferentes. Os estudantes perceberam que precisariam de ajuda de funcionários da escola, de professores e, provavelmente, da direção da escola. Sugerimos que, para o encontro seguinte, os estudantes assistissem a um curta-metragem chamado llha das flores.

Continuamos a conversa, elencando outros elementos que poderiam ser aspectos negativos durante o momento em que a merenda era consumida nas escolas públicas. Questionamos se o ambiente era adequado e limpo. Ronaldo respondeu que havia escolas na cidade em que serviam a comida, mas não ofereciam um espaço adequado para comer. Relatou que as pessoas comiam em qualquer lugar, costumavam ficar espalhadas pela escola. Ao final da merenda, uma pessoa passava recolhendo os utensílios, que chegavam a ser deixados no chão. Ronaldo explicou que esse não era um problema da sua escola, pois lá havia um refeitório limpo, com duas portas, uma para entrada e outra para saída.

Outra preocupação discutida foi a gestão financeira dos alimentos. Andreia afirmou que havia ouvido que a escola recebia em torno de $\mathrm{R} \$ 0,30$ por aluno/dia para compra da merenda. Na conversa, concluímos que esse valor não era suficiente para a alimentação, e que provavelmente a escola administrava o dinheiro comprando alimentos mais baratos ou contando com o fato de que muitos alunos não comiam. Ronaldo disse acreditar que muitos estudantes não comiam na escola por vergonha, e outros poderiam estar desperdiçando os alimentos por ficarem constrangidos de serem julgados por colegas pela quantidade que comiam.

Ronaldo acreditava que o desperdício dependia da qualidade servida no dia. Ele comparou arroz e macarrão e citou que muitas vezes o macarrão era servido sem tempero, o que fazia as pessoas jogarem fora. Ele acreditava que o desperdício da sopa 
era menor do que nos outros dias, porque somente as pessoas que queriam comer frequentavam o refeitório, ou seja, a sopa diminuía o consumo de alimento. Foi pedido que anotassem que era importante descobrir qual alimento causava maior desperdício. Ao final do encontro, Ronaldo relatou que esse assunto era discutido todos os anos, no entanto, não havia transparência. A direção da escola perguntava sobre a preferência dos estudantes, mas nunca havia uma devolutiva para eles. A conversa continuou sobre os funcionários. Os estudantes relataram que as mesmas pessoas que trabalhavam na limpeza eram as que ajudavam na cozinha. Informaram que usavam toucas, mas não luvas para servir. Também especulamos sobre outros assuntos (formação, higiene, etc.).

No encontro seguinte fizemos uma discussão sobre o curta-metragem lha das flores, assistido pelos estudantes. Foi comentada a questão da pobreza, da miséria e da fome no Brasil nas décadas de 1980 e 90 . Os alunos relacionaram esse dado com os dias atuais e perceberam que a realidade mudou. Atualmente no Brasil uma parte muito pequena da população não tem acesso à escola, e ao menos nesse ambiente espera-se que as crianças tenham algo para se alimentar. Questionamos os estudantes se o filme os havia motivado de alguma forma e Ronaldo revelou sentir necessidade de conscientização sobre essas questões, e uma forma de promover isso seria comunicar os resultados da pesquisa dentro da própria escola. Andreia considerou que na escola havia espaço para construção de uma horta, que poderia ajudar no cardápio.

\section{Os objetivos da investigação e o plano de ação}

Andreia relatou que gostaria de conversar com a diretora da escola e explicar a ela o que pretendiam fazer durante o projeto. Ronaldo sugeriu que o Grêmio da escola também poderia ser convidado para participar. Pedimos que, antes de iniciarem os contatos, escrevessem sobre os objetivos da investigação. Andréia revelou que já havia se antecipado e escrito alguns tópicos sobre o que poderiam fazer. Solicitamos que ela os resumisse em uma frase, e ela respondeu que o objetivo seria evitar o desperdício de alimentos.

Questionamos se isso não seria o objetivo final e se eles não estavam se antecipando, ao dizer que havia desperdício de alimentos. Ronaldo disse que, com certeza, havia desperdício de alimentos. E relatou que tinha comido no refeitório naquele dia e, sentado ao lado do cesto de restos para observar, avaliou que a comida estava boa, mas notou que havia na fila algumas pessoas que depois jogavam comida fora. Perguntamos então se ele poderia dizer quanto. Ele ficou em dúvida e disse que a quantidade poderia variar. Pedimos que Andréia fizesse novamente a leitura do objetivo e, ao invés de utilizarem o verbo "evitar" empregassem um outro que desse a ideia de que iríamos investigar a situação. Ronaldo perguntou se poderíamos usar o verbo analisar e continuou: "Analisar se existe desperdício de alimentos na escola para traçar estratégias (levantar ações) de conscientização".

Ao longo dos encontros seguintes os estudantes traçaram estratégias de coletas de dados em duas etapas. Primeiro, fizeram uma lista de perguntas abertas aos estudantes e depois dessa lista fizeram perguntas que seriam direcionadas às cozinheiras.

Além das entrevistas, os estudantes traçaram um plano de ação em tópicos para coletar dados: colocar dois sacos separados, um para as meninas e outro para os 
meninos; saber quantos meninos e meninas se alimentam por dia; verificar se havia uma balança na escola; criar tabela com a quantidade de alunos por gênero e a quantidade de alimentos desperdiçados por gênero; saber qual é o peso do balde; criar uma tabela ou outro questionário para levantar dados estatísticos.

\section{O projeto e as inferências dos estudantes}

Os estudantes, por iniciativa própria, marcaram e tiveram uma conversa com a diretora da escola. Ronaldo informou que até aquele momento a diretora não sabia que os estudantes estavam participando do projeto, mas ela ficou feliz com a iniciativa. Os estudantes questionaram se o cardápio da escola era fixo. A diretora respondeu que naquele momento o cardápio poderia variar, porque a escola recebia verbas somente em abril, estávamos no mês de março de 2017. No momento da pesquisa na escola, estavam sendo servidos alimentos que haviam sobrado do ano anterior, como arroz, macarrão e outros não perecíveis. A diretora explicou que, em razão da dificuldade de gestão financeira, apenas depois daquele mês a escola conseguiria fixar um cardápio semanal. Ela ainda disse aos estudantes que o cardápio era elaborado por uma nutricionista da capital do Estado, mas que a escola tinha certa flexibilidade para escolher entre os alimentos sugeridos. Apenas a sopa deveria necessariamente ser servida pelo menos uma vez na semana. Ao final da conversa, a direção solicitou aos estudantes, que, antes de iniciar o projeto, levassem ao seu conhecimento as perguntas que pretendiam fazer e um plano de ação. A diretora disse a eles que ficaria feliz em assistir às suas apresentações, disponibilizaria os materiais necessários e ajudaria com o que fosse preciso para a execução. Ainda, de acordo com Andreia, sugeriu que verificassem a aceitação de cada alimento por dias da semana.

Os estudantes também tiveram uma conversa informal com os colegas de sala. Relataram que nas conversas a sopa era o alimento mais referido como rejeitado. Ronaldo justificou que era por causa do calor da região e porque a sopa era servida às 9h30 da manhã. Segundo ele, nesse horário o sol já estava quente e por isso ouvia muitas pessoas reclamando. Além disso, a sopa costumava ser servida até três vezes por semana, em razão da falta de verbas no início do ano letivo. Ronaldo supôs que o desperdício de sopa deveria ser menor porque poucas pessoas frequentavam o refeitório naquele dia e provavelmente elas gostavam de sopa. Andreia relatou que os estudantes apontaram também que o tempo de intervalo era muito curto para comer - tinham 20 minutos -, e isso os obrigava a tomar uma decisão: ou comiam ou ficavam fora da sala. Na sua opinião, esse podia também ser um dos motivos de desperdício.

Os estudantes também fizeram entrevistas com as cozinheiras, e o que mais chamou a atenção de Ronaldo foi que, enquanto faziam a entrevista, as cozinheiras estavam comendo. Sem cerimônia, elas jogaram restos dos pratos no lixo, o que, para Ronaldo, era incoerente. Segundo ele, se elas não sabiam o quanto era suficiente colocar no seu próprio prato, como poderiam servir os alunos de maneira adequada? As cozinheiras informaram que os restos de alimentos eram utilizados para criação de porcos. Ronaldo e Andreia fizeram relação dessa situação com o curta-metragem a que assistiram. Outras situações foram também discutidas pelos estudantes, porém não serão reportadas aqui. 


\section{Os resultados da pesquisa dos estudantes}

Andreia e Ronaldo optaram por começar a investigação no momento em que o cardápio da escola fosse definido. Essa foi uma sugestão também da direção. Para coletar dados, os estudantes usaram uma tabela diária que continha os seguintes campos: data, desperdício masculino, desperdício feminino, quantidade de meninos servidos, quantidade de meninas servidas, tipo de comida servida, total de pessoas e tempo na fila. Antes de iniciar a coleta de dados, para poder medir o desperdício corretamente, passaram nas salas explicando o projeto e orientando os colegas que os restos deveriam ser jogados nos baldes que estavam separados por gênero. Disseram que, desde o primeiro dia do projeto, observaram que não havia mais pratos sendo deixados nas mesas. Para medir o tempo de espera, entregavam um cartão para o último aluno e cronometravam quanto tempo levaria até ele chegar à mesa de servir.

Os estudantes coletaram dados por aproximadamente um mês, analisaram os dados, agruparam, fizeram gráficos e no final produziram um relatório sobre suas observações. A Tabela 3 é um exemplo do material produzido pelos estudantes.

Tabela 3: Consumo no restaurante escolar no período de maio e junho de 2017

\begin{tabular}{|c|c|c|c|c|c|c|c|}
\hline Refeição & $\begin{array}{l}\text { Números de } \\
\text { dias servido }\end{array}$ & $\begin{array}{l}\text { Quantidade } \\
\text { de pessoas }\end{array}$ & $\begin{array}{l}\text { Média diária } \\
\text { no refeitório }\end{array}$ & $\begin{array}{l}\text { Desperdício } \\
\text { Total }(\mathrm{Kg})\end{array}$ & $\begin{array}{l}\text { Desperdício } \\
\text { Médio }\end{array}$ & $\begin{array}{l}\text { Tempo na fila } \\
\text { (min) }\end{array}$ & $\begin{array}{l}\text { Média de tempo } \\
\text { na fila (min) }\end{array}$ \\
\hline $\begin{array}{l}\text { Arroz com linguiça, cenoura } \\
\text { ralada e salada }\end{array}$ & 1 & 181 & 181 & 6,4 & 6,4 & 15 & 15 \\
\hline Baião de três com salada & 2 & 443 & 222 & 9,8 & 4,9 & 25 & 12,5 \\
\hline $\begin{array}{l}\text { Carne moída com batata, } \\
\text { cenoura, arroz e feijão }\end{array}$ & 4 & 932 & 233 & 20,3 & 5,1 & 62 & 15,5 \\
\hline Galinhada & 2 & 438 & 219 & 7,7 & 3,9 & 27 & 13,5 \\
\hline Macarrão à Bolonhesa & 2 & 397 & 199 & 3,6 & 1,8 & 26 & 13 \\
\hline Pão com carne moída & 1 & 214 & 214 & 0 & 0 & 11 & 11 \\
\hline Polenta, arroz e feijão & 5 & 1019 & 204 & 33,1 & 6,6 & 80 & 16 \\
\hline Sopa & 6 & 759 & 127 & 24,1 & 4,0 & 55 & 9,2 \\
\hline Vaca atolada e salada & 2 & 461 & 231 & 16,5 & 8,3 & 35 & 17,5 \\
\hline Total & 25 & 4844 & & 121,5 & 4,5 & & \\
\hline
\end{tabular}

Fonte: Arquivo do pesquisador

Além desses dados, os estudantes também verificaram o desperdício individual por gênero. Calcularam a média de desperdício por gênero, a média de frequência por gênero no refeitório, de tempo de espera e produziram diferentes gráficos. Até o momento da produção deste artigo, o projeto não havia sido finalizado, embora os estudantes já tivessem iniciado o relatório final. A seguir, um trecho do relatório:

[...] Passando os dias, analisando tudo aquilo, pudemos ver que o tempo gasto na fila e o desperdício de alimento variavam bastante dependendo do tipo da refeição servida. Vários alunos antes mesmo de iniciar a refeição, jogavam parte da sua comida fora por não gostarem de algum alimento que havia sido colocado no seu prato. Quando o tempo era insuficiente, o desperdício parecia ser maior, pois frequentemente sobrava alunos que ficavam comendo após o término do intervalo, por isto muitos deles não terminavam de comer e acabavam jogando a comida fora.

Temos como exemplo os dias em que foram servidos no cardápio vaca atolada com salada. Essa foi a refeição que mais tomou tempo para ser servida e teve o maior índice de desperdício, comparando com as outras refeições. Observamos que muitos alunos, antes mesmo de começarem a comer, jogavam a salada fora. 
A maioria disse que não gostava de salada no meio da refeição ou porque a mesma estava sem tempero, muitos pediam para não colocar a salada. Os funcionários optavam por não tirar porque isso tomava tempo.

Pudemos notar também que a sopa foi a refeição mais servida enquanto fizemos a pesquisa. Havia uma média muito menor de pessoas que frequentaram o refeitório, com relação ao desperdício não foi o menor nem o maior comparado as outras refeições. O tempo para servir era mais curto, já que o consumo era menor. Em todos os tipos de comida a quantidade de meninas que se alimentavam eram sempre superior à quantidade de meninos, assim inicialmente achávamos que as meninas ao fim da pesquisa desperdiçariam mais que os meninos. Mas com os resultados que obtivemos, notamos que os desperdícios comparados por ambas as partes têm em si pouca diferença.

Durante a elaboração desse relatório, procuramos não fazer intervenções, para verificar se os estudantes haviam adquirido autonomia ao longo da pesquisa. Pretendemos dar continuidade ao projeto com os estudantes, comunicando seus resultados em diferentes ambientes, inclusive na escola.

\section{Considerações Finais}

Várias perguntas devem emergir deste texto. Talvez, durante a leitura haja uma tentativa de adjetivar alguns dos atores como subordinados ou insubordinados. É preciso que fique claro ao leitor que entendemos a insubordinação criativa como atos políticos ao ensinar, atos que levem os sujeitos a emancipar-se das amarras burocráticas do sistema educacional. Não compreendemos a insubordinação como um atributo de quem pratica o ato, mas como uma ação que visa à construção da justiça social, com o aprendiz ao centro.

Ao se questionar se seria possível e viável aplicar um projeto de Educação Estatística ao longo de um ano letivo, outras questões podem incomodar os leitores. É preciso primeiro ter em mente que somente uma formação crítica e emancipatória ajudará a superar as amarras dos atos simplificados que foram assimilados ao longo da carreira. Professores que não produzem informação terão dificuldade de ensinar estudantes a fazê-lo e, além disso, possivelmente não compreenderão a importância do ato político.

Questões sobre currículo, avaliação e eficácia virão à tona. Ao responder essas questões, deve-se refletir sobre se estamos levando em consideração um currículo proposto ou imposto, e por quem. No caso das avaliações, os agentes educacionais devem se perguntar: estão tendo em vista avaliar a formação do sujeito ao longo do processo de aprendizagem, ou continuam a avaliar as respostas padronizadas que estimulam atos simplificados ao final do processo de ensino? Por último, tratando-se de eficácia no processo educacional, o olhar está voltado para todos ou para cada um?

É difícil saber qual a resposta dos estudantes, ao serem colocados diante de uma estrutura dialética de ensino. Essa forma de ensinar não permite atos simplificados. $\mathrm{O}$ ato de insubordinação criativa deve colocar o estudante individualmente e coletivamente no centro do processo de ensino. Segundo D'Ambrosio (2015), quando se faz isso, deve-se assumir o compromisso de criar ambientes educacionais em que haja apoio aos sujeitos, em que se potencialize o desenvolvimento do indivíduo como um ser viável, vibrante, criativo, moral, responsável, confiante, colaborativo, capaz de amar e de se preocupar com o bem-estar e a dignidade de todas as pessoas a sua volta. Os agentes educacionais 
devem ser conscientizados de que ainda há liberdade de escolha dos caminhos pedagógicos que poderão seguir.

\section{Referências}

ARTEAGA, $P$. et al. El lenguage de los gráficos estadísticos. UNION: Revista Iberoamericana de Educación Matemática, n. 18, p. 93-104, jun. 2009. Disponível em: http://www.fisem.org/www/union/revista18.php

BALDI B.; MOORE, D. A prática da Estatística nas ciências da vida. 2. ed. Rio de Janeiro: LTC Livros Técnicos e Cientificos Editora, 2014,

COUTINHO, C. et al. Investigação acção: metodologia preferencial nas práticas educativas. Psicologia Educação e Cultura, Braga - Portugal, v. 13, n. 2, p. 445-479, 2009.

COUTINHO, C.; SILVA, M.; ALMOULOUD, S. Desenvolvimento do pensamento estatístico e sua articulação com a mobilização de registros de representação semiótica. Bolema, Rio Claro, v. 24, n. 39, p. 495-511, 2011.

D'AMBROSIO, B. A subversão responsável na constituição do educador matemático. Em: Encontro Colombiano de Matemática Educativa, 16., de 5 a 7 de outubro de 2015, Bogotá, Colômbia. Anais... Bogotá, 2015, p.1-8.

D'AMBROSIO, B.; LOPES, C. Insubordinação criativa: um convite à reinvenção do educador matemático. Bolema, Rio Claro, v. 29, n. 51, p. 1-17, 2015.

FRIEL, S.; CURSIO, F.; BRIGHT, G. Making sense of graphs: Critical factors influencing comprehension and instructional implications. Journal for research in Mathematics Education, Reston, v. 32, n. 2, p. 124-158, 2001.

GÖTTEMS, C. Direito fundamental à educação. Argumenta Journal Law, Jacarezinho, v. 16, n. 16, p. 43-62, 2012.

GRABAUSKA, C.; BASTOS, F. Investigação ação educacional: possibilidades críticas e emancipatórias na prática educativa, Revista Eletrónica de Investigación Curricular y Educativa, Ensenada - México, v. 1, n. 2, p. 1-12, 1998.

GUTIÉRREZ, R. Embracing the inherent tensions in teaching mathematics from an equity stance. Democracy and Education, Portland, v. 18, n. 3, p. 9-16, 2009.

GUTIÉRREZ, R. Why (urban) mathematics teachers need political knowledge. Journal of Urban Mathematics Education, Atlanta, v. 6, n. 2, p. 7-19, 2013.

HAYNES, E.; LICATA, J. Creative insubordination of school principals and the legitimacy of the justifiable. Journal of Educational Administration, Bingley - Inglaterra, v. 33, n. 4, p. 21-35, 1995.

HENRIQUES, A.; OLIVEIRA, H. Investigações Estatísticas: um caminho a seguir. Educação e Matemática, Lisboa - Portugal, v. 120, n. 1, p. 3-8, 2012.

LIPSKY, M. Street level bureaucracy and the analysis of urban reform. Urban Affairs Quarterly, Bethesda, v. 6, n. 4, p. 391-409, 1971.

PFANNKUCH M.; REGAN, M.; WILD C. Telling data stories: Essential dialogues for comparative reasoning. Journal of Statistics Education, Online American Statistical Association, v. 18, n. 1 p. 1-38, 2010.

Submissão: 10/08/2017

Aceite: $28 / 11 / 2017$ 